\title{
Estimation of production of the copepod Calanus sinicus during spring in the northern East China Sea
}

\author{
HyUNG-Ku KANG ${ }^{1, *} \&$ CHEOL-Ho KIM ${ }^{2}$ \\ ${ }^{1}$ Marine Ecosystem Research Center, Korea Institute of Ocean Science \& Technology (KIOST), Busan 49111, South Korea \\ ${ }^{2}$ Ocean Circulation and Climate Research Center, KIOST, Busan 49111, South Korea
}

Received 9 March 2020; Accepted 27 July 2020 Responsible Editor: Koichi Ara

doi: $10.3800 /$ pbr.16.1

\begin{abstract}
We estimated the production of the copepod Calanus sinicus, including somatic production of copepodite stage $1(\mathrm{CI})$ to copepodite stage $5(\mathrm{CV})$ and egg production of adult females, to elucidate the role of $C$. sinicus during spring in the northern East China Sea, including the southern waters of Korea. To estimate the somatic production of the copepodites, an empirical equation for broadcasters (Hirst \& Bunker 2003) was used. The total biomass of the C. sinicus population, including CI to adult males and females, ranged from 0.11 to $30.23 \mathrm{mg} \mathrm{C} \mathrm{m}^{-3}$, with a mean of $8.69 \mathrm{mg} \mathrm{C} \mathrm{m}^{-3}$. The egg production rate (EPR) of adult females of C. sinicus, measured over $24 \mathrm{~h}$ of shipboard incubation, ranged from 0 to 14.9 eggs female ${ }^{-1}$ day $^{-1}$ (mean 5.8 eggs female $^{-1}$ day $^{-1}$ ), equivalent to mean $33.6 \mu \mathrm{g}$ $\mathrm{C} \mathrm{m}^{-3}$ day $^{-1}$. The weight-specific EPR (WSEPR) of adult females averaged $0.023 \mathrm{day}^{-1}$, and significantly increased with increasing water temperature at $5 \mathrm{~m}$ depth and surface chlorophyll $a$ concentration, respectively. WSEPR decreased with increasing body mass of individual adult females. The total production of the $C$. sinicus population ranged from 0.02 to $3.67 \mathrm{mg} \mathrm{C} \mathrm{m}^{-3}$ day $^{-1}$ (mean $0.91 \mathrm{mg} \mathrm{C} \mathrm{m}^{-3}$ day $^{-1}$ ) and the depth-integrated mean total production was estimated to be $52.72 \mathrm{mg} \mathrm{C} \mathrm{m}^{-2}$ day $^{-1}$. CV production accounted for $54 \%$ of the total production. By contrast, EPR contributed on average only $3.7 \%$ of the total production rate. Our estimate of the production of $C$. sinicus can be applied for potential comparisons of region-specific copepod production.
\end{abstract}

Key words: Calanus sinicus, copepod, copepodites, egg production rate, somatic production

\section{Introduction}

Copepods are important grazers of phytoplankton and microzooplankton, as well as a trophic link in the pelagic food web between primary producers and higher trophic levels (Banse 1995, Kiørboe 1997, Calbet \& Saiz 2005). Measurement of secondary production of zooplankton is essential to understanding energy flow in marine ecosystems (Kimmerer 1987, Banse 1995, Verity \& Smetacek 1996). Data on secondary production of marine mesozooplankton are rare compared to data on primary production, possibly due to the lack of a simple and robust method for measuring secondary production of mesozooplankton (Hirst \& Bunker 2003, Hirst et al. 2005, Kimmerer et al. 2007, Yebra et al. 2017).

Secondary production of zooplankton consists of somat-

\footnotetext{
*Corresponding author: Hyung-Ku Kang; E-mail, kanghk@kiost.ac.kr
}

ic production (i.e. growth of juveniles) and egg production (i.e. fecundity of adult females) (Runge \& Roff 2000). In general, the egg production rate (EPR) of copepods is measured directly by incubating adult females for $24 \mathrm{~h}$ (Runge $\&$ Roff 2000). Somatic production can be measured by various methods, including both classical and biochemical methods (Kimmerer \& McKinnon 1987, Hirst \& Bunker 2003, Kimmerer et al. 2007, Yebra et al. 2017). However, because measuring the growth rate of juveniles directly is a difficult task, several empirically-based global equations have been suggested to estimate the growth rate and then predict the production of marine copepods (Hirst \& Lampitt 1998, Peterson et al. 2002, Hirst \& Bunker 2003). These equations may be valuable to predict growth and production of copepods when no reliable growth rate measurements are available (Peterson et al. 2002).

The northern East China Sea (ECS) has a complex current circulation system, including the Tsushima Warm Current, Taiwan Warm Current, Yellow Sea Coastal Cur- 
rent, and Changjiang Diluted Water (Chen et al. 1995, Lie et al. 2003, Chen \& Sheu 2006, Lie \& Cho 2016). These complicated environments provide a good spawning ground for important species in the fishery industry such as anchovies and hairtail (Chen et al. 1997, Kim et al. 2005). Many studies have examined the spatial and temporal variations in water mass, nutrients, chlorophyll $a(\mathrm{Chl}$ a), primary productivity, and mesozooplankton biomass and abundance in the northern ECS (Gong et al. 2006, MOF 2006, Zhang et al. 2007b, Kim et al. 2009, Choi et al. 2011, Hwang et al. 2013, Kang et al. 2015, Lie \& Cho 2016).

The copepod Calanus sinicus Brodsky, 1962 is widely distributed in the shelf around the northern Pacific Ocean (Uye 2000), and is also one of the dominant calanoid species in the Inland Sea of Japan (Uye \& Murase 1997, Uye 2000), the Yellow Sea, and the northern ECS (Kang \& Hong 1998, Zhang et al. 2005, Kang et al. 2007b, Huo et al. 2008, Kang et al. 2011, Kim \& Kang 2018). There have been many studies on the population dynamics (Kang \& Hong 1998, Pu et al. 2004, Kang et al. 2007b, Kang 2008, Kang et al. 2013), over-summering site (Wang et al. 2003), EPR (Park 1997, Zhang et al. 2007a, Huo et al. 2008, Wang et al. 2009, Kang et al. 2011), feeding (Huo et al. 2008, Kim \& Kang 2018), and somatic production (Kang 2008) of $C$. sinicus in the Yellow Sea and around the northern ECS, including the southern waters of Korea. However, little is known about secondary production of $C$. sinicus in the northern ECS.

The aims of this study were to evaluate the production of $C$. sinicus during spring in the northern ECS, including the southern waters of Korea, and to understand the controlling factors related to the fecundity of females.

\section{Materials and Methods}

\section{Field sampling}

The cruise for measuring production of the copepod Calanus sinicus was carried out from April 29 to May 8,2004 , at nine stations in the northern ECS, including the southern waters of Korea, on the R/V Eardo (Table 1, Fig. 1). Temperature and salinity were recorded with a conductivity-temperature-depth (CTD)-rosette (SBE 911, Sea-Bird Scientific, USA). To depict more detailed temperature and salinity conditions, temperature and salinity data from an additional 52 stations from the same cruise (MOF 2006) were used. To measure $\mathrm{Chl} a$ concentrations, water samples $(500 \mathrm{~mL})$ from various depths $(0,10,20,30,50,75$ and $100 \mathrm{~m}$ ) at the nine stations were filtered onto Whatman $\mathrm{GF} / \mathrm{F}$ glass filters $(47 \mathrm{~mm})$ during the cruise, placed into 1.8-mL cryogenic vials (Nalgene, Thermo Fisher Scientific, USA), and stored in liquid nitrogen until the end of cruise. After the cruise, the cryovial samples were transported to the laboratory on dry ice in an insulated box. In the laboratory, the filters in the cryogenic vials were
Table 1. Water depth, mean water temperature (WT) of the water column, mean chlorophyll $a(\mathrm{Chl} a)$ concentration of the water column, and mean body mass of adult female.

\begin{tabular}{lrrcc}
\hline Station & $\begin{array}{c}\text { Depth } \\
(\mathrm{m})\end{array}$ & $\begin{array}{c}\text { WT } \\
\left({ }^{\circ} \mathrm{C}\right)\end{array}$ & $\begin{array}{c}\mathrm{Chl} a \\
\left(\mu \mathrm{g} \mathrm{L}^{-1}\right)\end{array}$ & $\begin{array}{c}\text { Body mass of } \\
\text { adult female } \\
\left(\mu \mathrm{g} \mathrm{C} \mathrm{ind.}^{-1}\right)\end{array}$ \\
\hline Ieodo & 50 & 12.0 & 1.93 & 121.4 \\
B4 & 80 & 13.5 & 1.55 & 107.1 \\
B9 & 105 & 16.6 & 0.80 & 93.2 \\
D1 & 48 & 11.3 & 1.03 & 135.4 \\
D7 & 104 & 14.8 & 0.52 & 103.5 \\
D11 & 104 & 15.4 & 0.49 & 83.3 \\
H6 & 140 & 15.9 & 1.03 & 93.0 \\
H3 & 89 & 14.5 & 1.12 & 98.9 \\
H1 & 26 & 13.7 & 1.03 & 124.4 \\
\hline
\end{tabular}

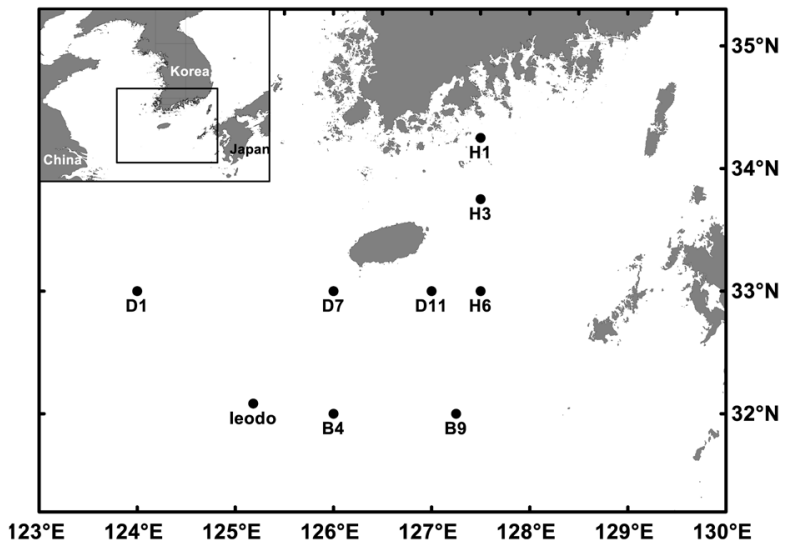

Fig. 1. Study area and sampling stations in the northern East China Sea including the southern waters of Korea.

placed into $7 \mathrm{~mL}$ of $90 \%$ acetone and maintained at $-20^{\circ} \mathrm{C}$ for $24 \mathrm{~h}$. The Chl $a$ concentration was measured using a fluorometer (10-AU, Turner Designs, USA) according to Parsons et al. (1984).

\section{Abundance and biomass}

Mesozooplankton were sampled using a vertical net tow from the near-bottom to the surface with a $0.5-\mathrm{m}$ diameter, 200- $\mu \mathrm{m}$ mesh net fitted with a flowmeter (Model 438-110, Hydro-bios, Germany) for estimating the volume filtered by the net. The samples were preserved in neutralized formalin at a $5 \%$ final concentration for subsequent analysis and transported to the laboratory. In the laboratory, the mesozooplankton samples from each station were identified as copepodite stage 1 (CI) through copepodite stage 5 (CV) and adult males and females of Calanus sinicus using a stereoscopic microscope (Stemi 2000-C, Zeiss, Germany), and counted to determine abundances. Also, the prosome length of each developmental stage of $C$. sinicus was measured using the stereomicroscope with an ocular micrometer. The carbon contents of $C$. sinicus individuals 
were estimated from the length-weight relationship (Uye 1988):

$$
\log _{10} \mathrm{BW}=-9.416+3.378 \log _{10} \mathrm{PL},
$$

where PL is the prosome length $(\mu \mathrm{m})$ for copepodites and $\mathrm{BW}$ is the body mass $(\mu \mathrm{g} \mathrm{C})$.

\section{EPR}

The EPR of Calanus sinicus was measured by the incubation method (Runge \& Roff 2000, Peterson et al. 2002). To measure EPR, adult females of $C$. sinicus were collected in a vertical net tow $(0.5 \mathrm{~m}$ in diameter, $200 \mu \mathrm{m}$ mesh size) from the near-bottom to the surface at the nine stations. Active and healthy adult female $C$. sinicus were sorted into 2-L glass bowls containing $64 \mu \mathrm{m}$ screened surface seawater. Two to four females of $C$. sinicus were placed in a polycarbonate bottle $(1 \mathrm{~L})$ containing $64 \mu \mathrm{m}$ screened surface seawater from each sampling station (Peterson et al. 2002), with two to ten replicate bottles depending on the sampling station, and the bottles were placed in a water bath in which surface seawater was circulated. It has been known that in some copepod species [e.g. Calanus finmarchicus (Gunnerus, 1770) and C. helgolandicus (Claus, 1863)] the feeding history of females prior to capture is important for EPR in the first $24 \mathrm{~h}$ after capture (Runge \& Roff 2000). Therefore, we assumed that EPR would not be biased by the $64 \mu \mathrm{m}$ screened surface seawater. We also assumed that the motion of the ship would help keep the phytoplankton in the bottles in suspension during the incubation. In addition, the bottles were manually rotated three or four times a day to prevent settlement of phytoplankton. After $24 \mathrm{~h}$, the contents of the bottles were filtered through a $64-\mu \mathrm{m}$ sieve to collect eggs and nauplii and the females were checked for viability. The eggs, nauplii, and females on the screen were preserved in 5\% neutralized formalin and kept in $20-\mathrm{mL}$ glass vials. The numbers of eggs and nauplii were counted, and the prosome lengths of adult females were measured using a stereomicroscope with an ocular micrometer to estimate body mass of the females. Egg cannibalism was also considered by counting crumpled egg membranes left in the vials (Runge \& Roff 2000) and eggshells in the fecal pellets (Kang 2012). Egg hatching success was not measured in the EPR experiment. EPR was expressed both as numbers of eggs per female per day (eggs female ${ }^{-1}$ day $^{-1}$ ) and as weight-specific EPR (WSEPR, day ${ }^{-1}$ ). The WSEPR of a female was calculated as the carbon content of total eggs spawned divided by the body weight of the adult female (Peterson et al. 2002). The carbon content of a $C$. sinicus egg (EC, $\mu \mathrm{g} \mathrm{C}$ ) was estimated from the egg diameter (ED, $\mu \mathrm{m}$ ) using the equation (Liang et al. 1994):

$$
\mathrm{EC}=\mathrm{ED}^{3.04} \times 10^{-7.27} .
$$

The ED was measured in the laboratory using a stereomicroscope with an ocular micrometer.

\section{Calculation of total production}

The total production rate of Calanus sinicus was calculated as the sum of egg production of adult females and somatic production of juveniles from $\mathrm{CI}$ to $\mathrm{CV}$, excluding adult males (Runge \& Roff 2000). The total production rate of the C. sinicus population ( $\mathrm{P}, \mathrm{mg} \mathrm{C} \mathrm{m}^{-3} \mathrm{day}^{-1}$ ) was calculated as follows:

$$
\mathrm{P}=\sum\left(\mathrm{B}_{\mathrm{i}} \times \mathrm{g}_{\mathrm{i}}\right)+\mathrm{B}_{\mathrm{f}} \times \mathrm{g}_{\mathrm{f}},
$$

where $B_{i}$ and $B_{f}$ are the biomass of juveniles and adult females, respectively; $g_{i}$ is the growth rate of juveniles; and $g_{f}$ is the WSEPR of adult females. In this study, we only considered $\mathrm{CI}$ to $\mathrm{CV}$ for somatic production, because a $200-\mu \mathrm{m}$ mesh net cannot effectively collect $C$. sinicus nauplii. To calculate the somatic production, it is necessary to know the growth rate of juveniles. Although there have been growth rate measurements of $C$. sinicus in the laboratory with excess food and temperature-dependent growth equations (Uye 1988), the production rates estimated by these equations might be overestimated for $C$. sinicus in food-limited conditions such as in the northern ECS. Therefore, the growth rate $\left(\mathrm{g}, \mathrm{day}^{-1}\right)$ of juvenile $C$. sinicus was estimated from an empirical equation for broadcasters (from Table 6 in Hirst \& Bunker 2003) as:

$$
\begin{aligned}
\log _{10} g= & -0.0143 \mathrm{~T}-0.363 \log _{10} \mathrm{BW} \\
& +0.135 \log _{10} \text { Chl } a-0.105,
\end{aligned}
$$

where $\mathrm{T}$ is water temperature $\left({ }^{\circ} \mathrm{C}\right), \mathrm{BW}$ is individual body mass $(\mu \mathrm{g} \mathrm{C})$, and $\mathrm{Chl} a$ is chlorophyll $a$ concentration $\left(\mu \mathrm{g} \mathrm{L}^{-1}\right)$. We used mean water temperature of the water column at each station for $\mathrm{T}$, mean body mass of $\mathrm{CI}$ to $\mathrm{CV}$ from all stations for $\mathrm{BW}$, and mean $\mathrm{Chl} a$ concentration of the water column at each station for $\mathrm{Chl} a$.

\section{Statistics}

Correlation analyses were conducted between WSEPR $(n=52$, pooled data) and the water temperature $(5 \mathrm{~m}$ depth and mean of water column temperature, $n=6)$, Chl $a$ concentration (surface and mean of water column Chl $a$ concentration, $n=6)$, and mean body mass $(n=6)$ at each station. The same analyses were also applied to EPR with the water temperature and $\mathrm{Chl} a$ concentration at each station.

\section{Results}

\section{Temperature, salinity, and $\mathrm{Chl} \boldsymbol{a}$ concentration}

During the cruise, the water temperature at $5 \mathrm{~m}$ depth ranged from 12.2 to $19.1{ }^{\circ} \mathrm{C}$ (mean $15.2^{\circ} \mathrm{C}$ ), and was relatively higher in the eastern part $\left(>15.0^{\circ} \mathrm{C}\right)$ and lower in the western part (Fig. 2a). The mean water temperature of the water column ranged from 11.3 to $16.6^{\circ} \mathrm{C}$ (Table 1). The salinity at $5 \mathrm{~m}$ depth ranged from 32.17 to 34.49 , and was higher in the eastern part than in the western part (Fig. 2b). The mean salinity of the water column ranged from 32.30 
(a)

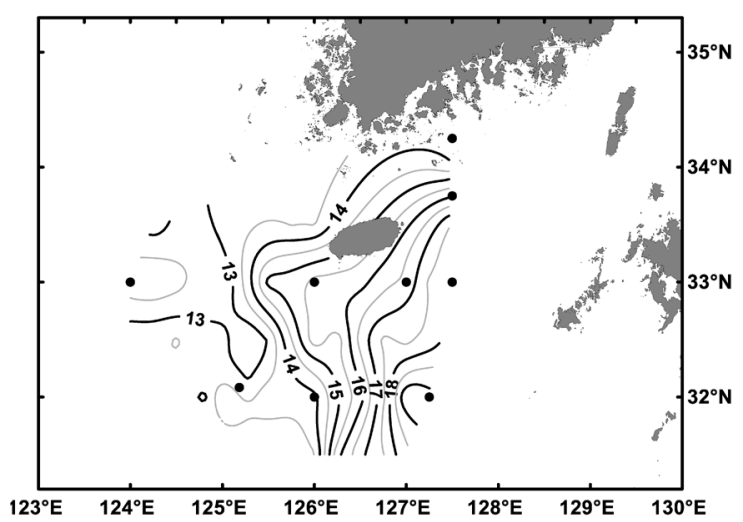

(b)

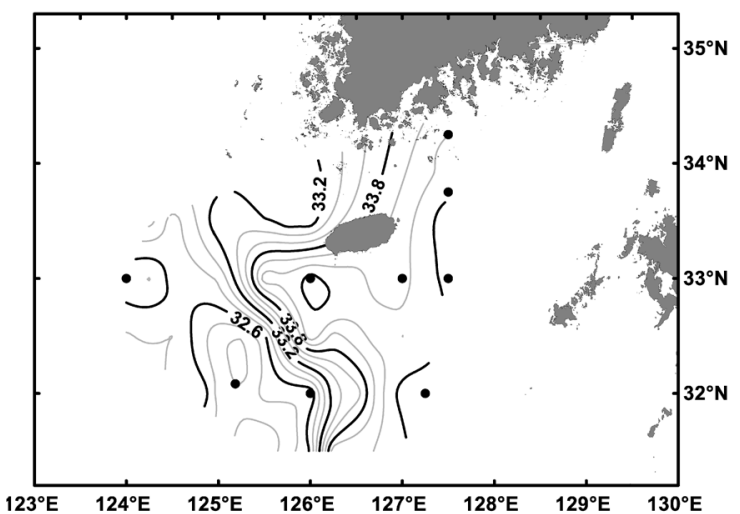

(c)

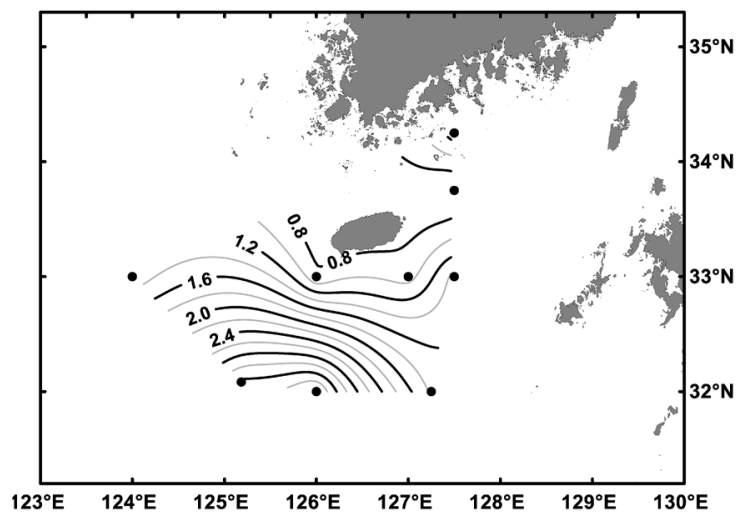

Fig. 2. Spatial distribution of (a) water temperature at $5 \mathrm{~m}$ depth, (b) salinity at $5 \mathrm{~m}$ depth, and (c) surface $\mathrm{Chl} a$ concentration.

to 34.52 (mean 33.88). The surface $\mathrm{Chl} a$ concentration ranged from 0.57 to $3.65 \mu \mathrm{g} \mathrm{L}^{-1}$ (mean $1.7 \mu \mathrm{g} \mathrm{L}^{-1}$ ) and was relatively higher in the southwestern part (e.g. Ieodo station and station B4) at $>3 \mu \mathrm{g} \mathrm{L}^{-1}$, and lower in the northeastern part (e.g. stations $\mathrm{H} 3, \mathrm{D} 7$, and D11) at $<1 \mu \mathrm{g} \mathrm{L}^{-1}$ (Fig. 2c). The mean Chl $a$ concentration of the water column ranged from 0.52 to $1.93 \mu \mathrm{g} \mathrm{L}^{-1}$ (Table 1).

\section{Abundance and biomass of Calanus sinicus}

The total abundance of CI to adult males and females of Calanus sinicus varied by station, ranging from 3 to 1,117



Fig. 3. Variation of abundance of copepodite stage 1 (CI) to adult males and females of Calanus sinicus.

ind. $\mathrm{m}^{-3}$ (mean 256 ind. $\mathrm{m}^{-3}$ ), and was highest at Ieodo station, followed by station H1, and lowest at station H6 (Fig. 3 ). The total biomass of $\mathrm{CI}$ to adult males and females varied by station, ranging from 0.11 to $30.23 \mathrm{mg} \mathrm{C} \mathrm{m}^{-3}$ (mean $8.69 \mathrm{mg} \mathrm{C} \mathrm{m}^{-3}$ ), and was highest at station $\mathrm{H1}$, followed by Ieodo station, and lowest at station H6 (Fig. 4a). However, when we only consider the biomass of CI to CV (excluding adult males and females), which contribute to the somatic production of $C$. sinicus, the biomass ranged from 0.11 to $19.81 \mathrm{mg} \mathrm{C} \mathrm{m}^{-3}$ (mean $5.49 \mathrm{~m} \mathrm{C} \mathrm{m}^{-3}$ ), with the highest at Ieodo station, followed by station H1, and the lowest at station H6 (Fig. 4a). The biomass of adult females varied by station, ranging from 0.004 to $18.15 \mathrm{mg} \mathrm{C} \mathrm{m}^{-3}$ (mean $2.72 \mathrm{mg} \mathrm{C} \mathrm{m}^{-3}$ ), with the highest at station $\mathrm{H} 1$ (Fig. 4a). The biomass of $\mathrm{CV}$ also varied by station, ranging from 0.08 to $10.97 \mathrm{mg} \mathrm{C} \mathrm{m}^{-3}$ (mean $3.71 \mathrm{mg} \mathrm{C} \mathrm{m}^{-3}$ ), with the highest at Ieodo station (Fig. 4a). The percent biomass of $\mathrm{CI}$ to adult males and females varied by station; CV had the highest percent biomass with a mean of $42.7 \%$, followed by adult females (31.3\%) and CIV (13.5\%), and the lowest was CI (Fig. 4b). The percent biomass of adult females was the highest at station H1 (60.1\%), followed by station D1 (40.8\%), and the lowest was station D11 (1.9\%) (Fig. 4b).

\section{Egg production rate}

The mean egg diameter of Calanus sinicus was $162 \pm 9.5 \mu \mathrm{m}(n=93 \mathrm{eggs})$ and egg carbon content was estimated to be $0.28 \pm 0.05 \mu \mathrm{g} \mathrm{C} \mathrm{egg}^{-1}$. The EPR of $C$. sinicus ranged from 0 to 14.9 eggs female ${ }^{-1}$ day $^{-1}$ (mean 5.8 eggs female ${ }^{-1}$ day $^{-1}$ ) and was relatively high at stations B4 and B9. However, the females at stations D7, D11, and H6 did not spawn eggs (Fig. 5a). The body mass of an adult female varied by station, from 93.0 to $124.4 \mu \mathrm{g} \mathrm{C}$ ind. ${ }^{-1}$ (mean $106.7 \mu \mathrm{g} \mathrm{C}_{\text {ind. }}^{-1}$ ) (Table 1). The WSEPR of C. sinicus ranged from 0.003 to 0.044 day $^{-1}$ (mean 0.023 day $^{-1}$ ) when excluding the stations where female fecundity were zero. The population EPR of $C$. sinicus, calcu- 
(a)

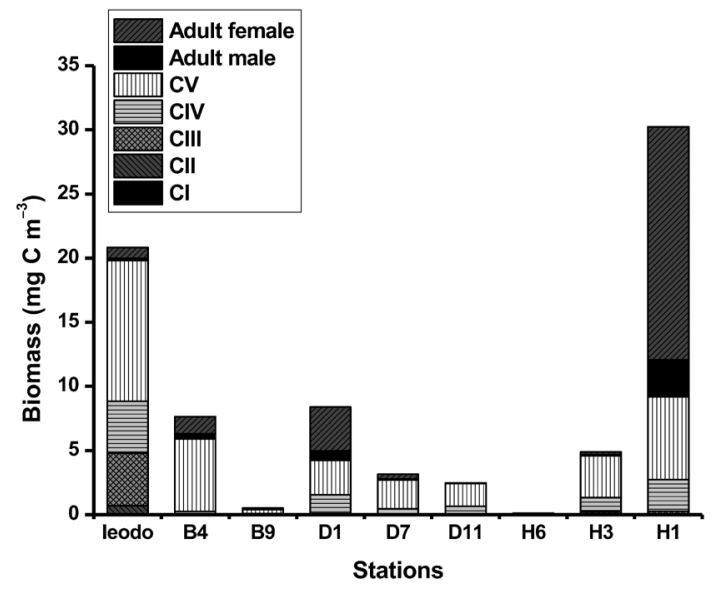

(b)

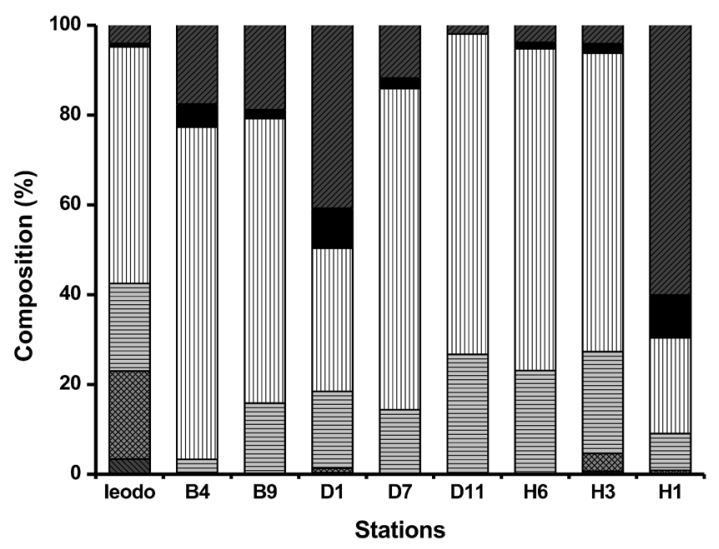

Fig. 4. Variations of (a) biomass and (b) percent biomass of copepodite stage $1(\mathrm{CI})$ to adult males and females of Calanus sinicus.

lated from the WSEPR multiplied by the adult female biomass, ranged from 0 to $217.8 \mu \mathrm{g} \mathrm{C} \mathrm{m}^{-3} \mathrm{day}^{-1}$ (mean $33.6 \mu \mathrm{g} \mathrm{C} \mathrm{m}^{-3}$ day $^{-1}$ ), with the highest at station $\mathrm{H1}$, followed by station B4 (Fig. 5b), showing a different spatial variation of population EPR compared to the female EPR as eggs per female per day.

\section{Production of Calanus sinicus}

Somatic production of $\mathrm{CI}$ to $\mathrm{CV}$ of Calanus sinicus ranged from 0.02 to $3.66 \mathrm{mg} \mathrm{C} \mathrm{m}^{-3} \mathrm{day}^{-1}$ (mean $0.88 \mathrm{mg} \mathrm{C} \mathrm{m}^{-3} \mathrm{day}^{-1}$ ) and was highest at Ieodo station, followed by station $\mathrm{H} 1 \quad\left(1.26 \mathrm{mg} \mathrm{C} \mathrm{m}^{-3}\right.$ day $\left.^{-1}\right)$, and lowest at station $\mathrm{H} 6\left(0.02 \mathrm{mg} \mathrm{C} \mathrm{m}^{-3}\right.$ day $\left.^{-1}\right)$. Total production (i.e. somatic production of $\mathrm{CI}$ to $\mathrm{CV}+\mathrm{EPR}$ of adult females) of $C$. sinicus varied by station, ranging from 0.02 to $3.67 \mathrm{mg} \mathrm{C} \mathrm{m}^{-3}$ day $^{-1}$ with a mean of $0.91 \mathrm{mg} \mathrm{C} \mathrm{m}^{-3}$ day $^{-1}$, and was highest at Ieodo station, followed by the nearest coastal station (H1), and lowest at station H6 (Fig. 6a). The variation in total production of $C$. sinicus was similar to that of somatic production. Depth-integrated total production of $C$. sinicus ranged from 3.38 to (a)



(b)



Fig. 5. Variations of egg production rate of Calanus sinicus: (a) number of eggs of an adult female and (b) adult female population in terms of carbon.

$183.46 \mathrm{mg} \mathrm{C} \mathrm{m}^{-2} \mathrm{day}^{-1}$ (mean $52.72 \mathrm{mg} \mathrm{C} \mathrm{m}^{-2} \mathrm{day}^{-1}$ ), and was highest at Ieodo station, followed by station B4, D11, and H3 (Fig. 6b).

The percent ratio of EPR (including zero EPR) to the total production ranged from 0 to $14.7 \%$ (mean $3.7 \%$ ), indicating that the contribution of EPR to the total production was very low, and most $C$. sinicus production was dependent on somatic production from juvenile growth of CI to $\mathrm{CV}$. When we excluded zero EPR stations, the ratio ranged from 0.4 to $17.7 \%$ (mean $4.1 \%$ ).

\section{Factors affecting fecundity of Calanus sinicus}

The EPR of Calanus sinicus ( $n=52$, pooled data excluding stations with zero spawning) at 9 stations was positively correlated with water temperature at $5 \mathrm{~m}$ depth $(n=6$, excluding the stations with zero spawning, $p<0.001$; Fig. $7 \mathrm{a})$, mean water temperature of the water column $(n=6$, $p<0.0001)$, and surface Chl $a$ concentration $(n=6, p<0.05$; Fig. 7b), but not mean Chl $a$ concentration of the water column $(n=6, p>0.05)$. The WSEPR of $C$. sinicus $(n=52$, pooled data excluding stations with zero spawning) was also positively correlated with water temperature at $5 \mathrm{~m}$ depth $(n=6$, excluding the stations with zero spawning, $p<0.0001$; Fig. 8a), mean water temperature of the water column ( $n=6, p<0.0001)$, and surface $\mathrm{Chl} a$ concentration $(n=6, p<0.05$; Fig. 8 b), but not mean Chl $a$ concentration of the water column $(n=6, p>0.05)$. However, WSEPR 
(a)

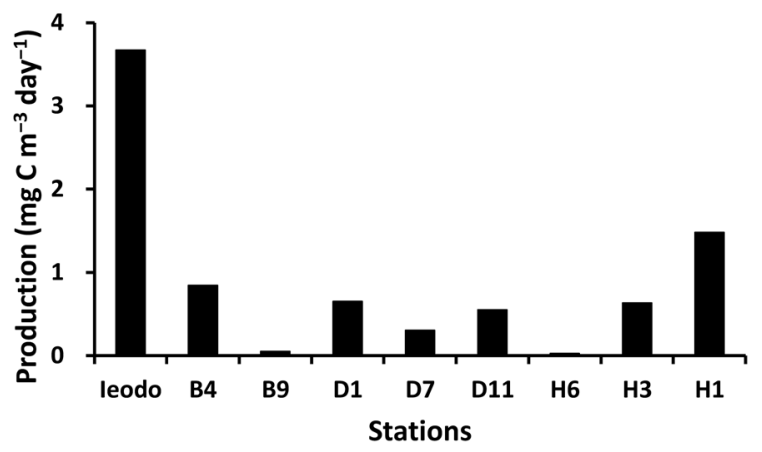

(b)

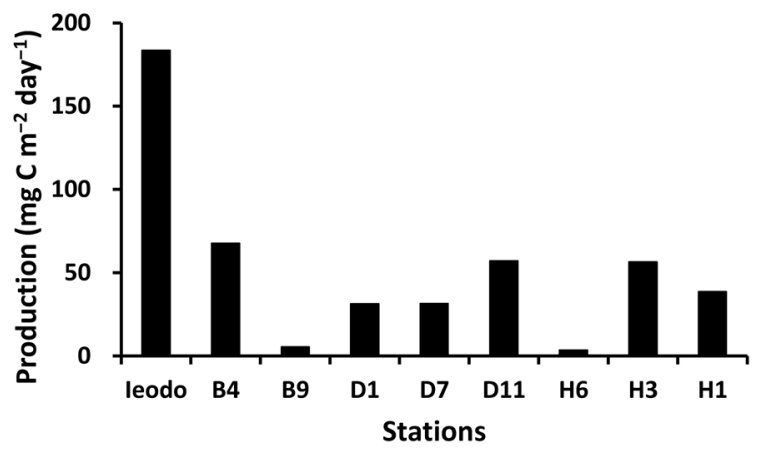

Fig. 6. Variations of total production of Calanus sinicus (e.g. somatic production of copepodite stage $1(\mathrm{CI})$ to copepodite stage 5 (CV) plus egg production rate): (a) mean production of water column and (b) depth-integrated production.

was negatively correlated with mean of female body mass ( $n=6, p<0.0001$; Fig. $8 \mathrm{c}$ ), indicating that WSEPR decreases as the body mass of an adult female increases.

\section{Discussion}

\section{Abundance of Calanus sinicus}

There are several studies on the variation of abundance of Calanus sinicus in the Yellow Sea and the northern ECS. Kim \& Lim (1999) reported that the abundance of C. sinicus in the Yellow Sea was highest in April and June (239 ind. $\mathrm{m}^{-3}$ and 262 ind. $\mathrm{m}^{-3}$, respectively), followed by August (179 ind. $\mathrm{m}^{-3}$ ) and December (32 ind. $\mathrm{m}^{-3}$ ). Kang \& Hong (1998) reported that the abundance of $C$. sinicus, including copepodites, in the southern waters of Korea was highest in April and lowest in summer. Kang (2008) reported that the mean abundance of $C$. sinicus, including copepodites, was 96 ind $\mathrm{m}^{-3}$ in the northern ECS around Jeju Island in early summer, which was lower than that in our research (256 ind $\mathrm{m}^{-3}$ ). These results indicate that seasonal variation in $C$. sinicus abundance in the Yellow Sea and the northern ECS, including the southern waters of Korea, is similar among regions, with the highest abundance in spring. (a)

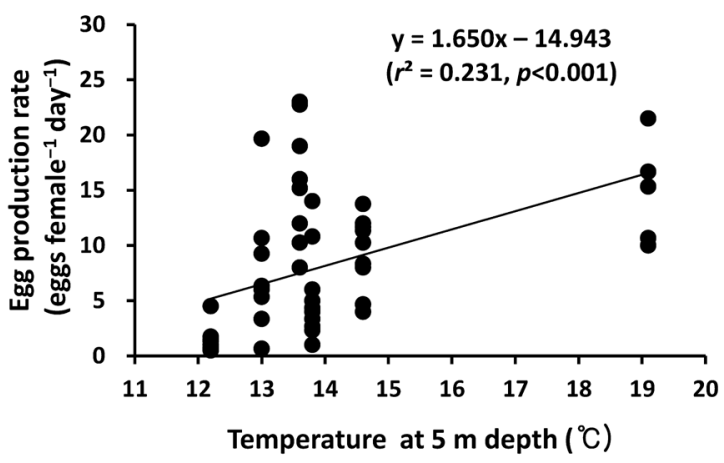

(b)

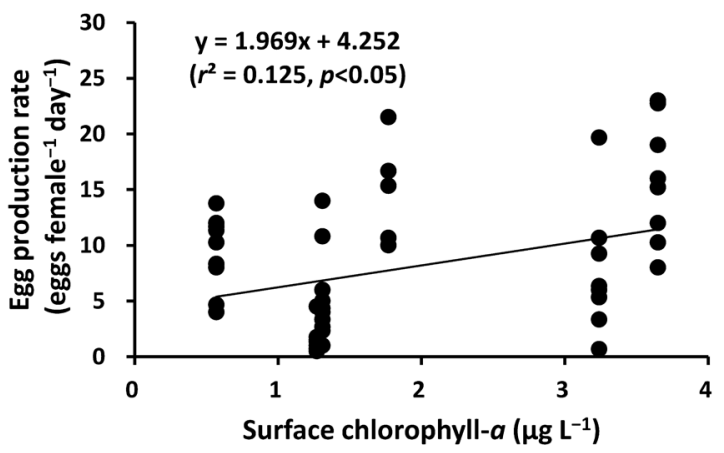

Fig. 7. Egg production rate of Calanus sinicus as a function of (a) water temperature at $5 \mathrm{~m}$ depth and (b) surface $\mathrm{Chl} a$ concentration.

\section{Egg production rate}

Our mean EPR of Calanus sinicus (5.8 eggs female ${ }^{-1}$ day $^{-1}$ ) was lower than those observed on the Korean coast of the Yellow Sea (Kang et al. 2011), the Asan Bay in spring (Park 1997), and the Yellow Sea (Wang et al. 2009), but similar to that of the southern Yellow Sea (Zhang et al. 2005), indicating that the EPR of C. sinicus in spring is much higher in the bay and coastal waters than offshore or in shelf waters (see Table 2).

Adult females of C. sinicus at stations D7, D11, and H6 did not spawn eggs during our study. Gonad maturity or gonad state, spawning timing (e.g. no eggs or not enough eggs after spawning or between spawning events), fertilization state, and feeding history of females have been known as potential causes of variability of egg production in Calanus spp. (Rey-Rassat et al. 2004, Niehoff 2007, Wang et al. 2009). However, we could not determine the potential causes of fecundity of $C$. sinicus; instead we randomly selected active and healthy adult females from the sample of the $C$. sinicus population and then incubated them for EPR experiments. Therefore, it is not clear why the females did not spawn during our research. In practice, it is recommended that zero spawning data should be included in egg production data to estimate the in situ EPR of the population (Runge \& Roff 2000).

The EPR of $C$. sinicus in this study significantly in- 
(a)

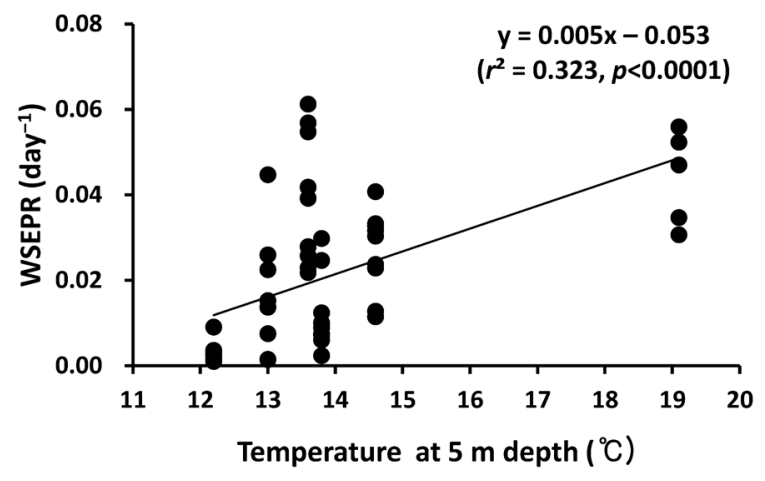

(b)

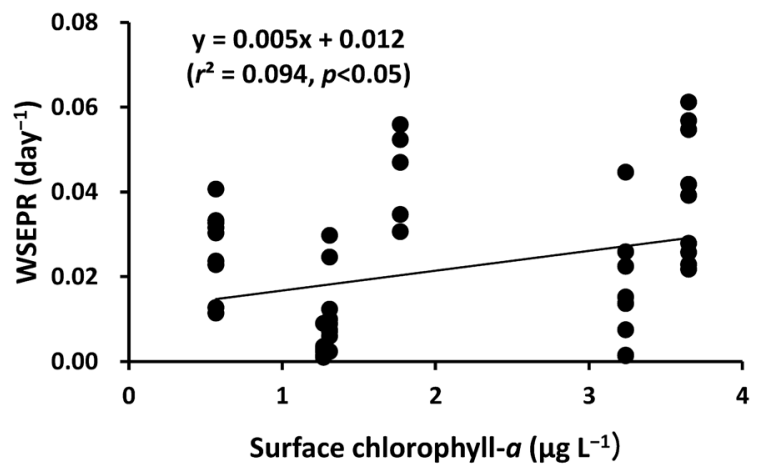

(c)

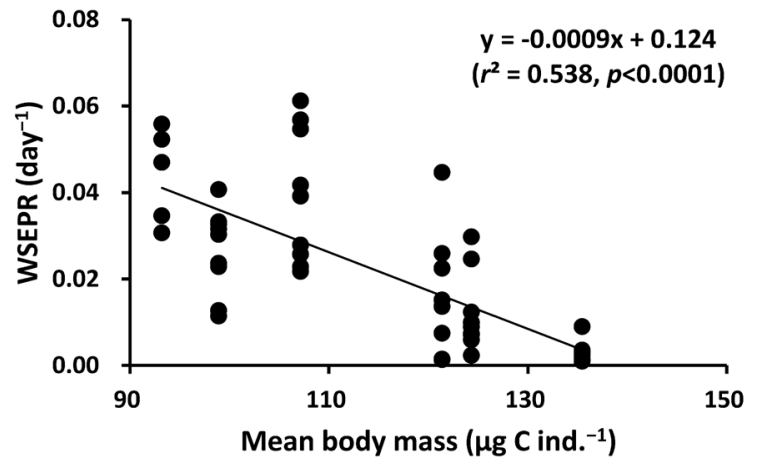

Fig. 8. Weight-specific egg production rate (WSEPR) of Calanus sinicus as a function of (a) water temperature at $5 \mathrm{~m}$ depth, (b) surface $\mathrm{Chl} a$ concentration, and (c) mean body mass of adult female.

creased with increasing Chl $a$ concentrations (Fig. 7b), with a range of 0.49 to $1.93 \mu \mathrm{g} \mathrm{L}^{-1}$, indicating that food availability, particularly phytoplankton, is an important determinant of fecundity of $C$. sinicus in spring as well as water temperature. Wang et al. (2009) showed that the EPR of $C$. sinicus in the Yellow Sea in April was generally coincident with the food availability (e.g. phytoplankton and ciliates). Kang et al. (2011) showed that adult females of $C$. sinicus in the Korean coastal waters of the Yellow Sea had a high mean fecundity from March through May (23.4 eggs female ${ }^{-1}$ day $^{-1}$ ), when Chl a concentrations were relatively high, ranging from 0.6 to $9.6 \mu \mathrm{g} \mathrm{L}^{-1}$ (mean
$5.3 \mu \mathrm{g} \mathrm{L}^{-1}$ ). Although phytoplankton is an important factor for fecundity of $C$. sinicu, it is likely that $\mathrm{Chl} a$ concentrations in this study were not enough for maximum EPR of C. sinicus. Copepods, particularly adult females, suffer from food limitation in the field (Peterson 1988, Hirst $\&$ Bunker 2003). Food limitation has a greater effect on female growth (i.e. EPR of adult females) than juvenile growth (Hirst \& Bunker 2003). Peterson et al. (2002) used the ratio of observed EPR to maximum EPR as a measure of the degree of limitation of growth by factors such as food and temperature. Kang et al. (2011) proposed in situ mean maximum EPR of $C$. sinicus in the Korean coastal waters of the Yellow Sea in spring as 50.4 eggs female ${ }^{-1}$ day $^{-1}$. In this study, the EPR of $C$. sinicus was very low compared to the mean maximum EPR of $C$. sinicus in the coastal waters and was $12 \%$ of the maximum EPR for $C$. sinicus. This result may indicate that potential food limitation in the study region was of great impact on the fecundity of $C$. sinicus in spring.

\section{Weight-specific egg production rate of Calanus sinicus}

The WSEPR of Calanus sinicus in this study was similar to that of C. sinicus in the southern Yellow Sea (Zhang et al. 2005). However, our value was lower than those for C. sinicus along the Korean coast of the Yellow Sea (Kang et al. 2011) and in the Asan Bay from January to November (Park 1997) (see Table 2). This comparison indicates that WSEPR of $C$. sinicus in spring is higher in the coastal regions than offshore, possibly due to differences in food availability for adult females for reproduction.

The WSEPR of $C$. sinicus significantly increased with increasing water temperatures at $5 \mathrm{~m}$ depth (Fig. 8a), although the temperature range during our research period was rather narrow $\left(12\right.$ to $\left.19^{\circ} \mathrm{C}\right)$. This result is consistent with the general relationship between WSEPR and temperature in adult broadcaster copepods (Hirst \& Bunker 2003). However, Kang et al. (2011) showed that the WSEPR of $C$. sinicus along the Korean coast of the Yellow Sea in spring was negatively correlated with temperature, and they suggested that the lower phytoplankton concentration at warmer surface temperatures was responsible for the result. Therefore, it is likely that water temperature can increase the WSEPR of adult females within a certain temperature range, but this effect might be influenced by food availability for females in the field.

The WSEPR of the broadcasters increased positively with surface Chl $a$ concentrations (Hirst \& Bunker 2003). Peterson et al. (2002) showed that the WSEPR of small and large copepods off the Oregon coast increased with Chl $a$ concentration at $3 \mathrm{~m}$ depth during summer. In this study, the WSEPR of $C$. sinicus significantly increased with increasing surface Chl $a$ concentrations (Fig. 8b), consistent with previous results (Peterson et al. 2002, Hirst \& Bunker 2003), indicating that the fecundity of $C$. sinicus in spring depends on phytoplankton diet. However, the coefficient of determination of the independent variable (i.e. surface $\mathrm{Chl}$ 
Table 2. Comparison of egg production rate (EPR) and weight-specific egg production rate (WSEPR) for Calanus sinicus with the season and water temperature (WT). Parentheses indicate mean value of EPR or WSEPR.

\begin{tabular}{llcccc}
\hline \multicolumn{1}{c}{ Region } & \multicolumn{1}{c}{ Season } & WT $\left({ }^{\circ} \mathrm{C}\right)$ & $\begin{array}{c}\text { EPR }(\text { eggs } \\
\left.\text { female } \text { day }^{-1}\right)\end{array}$ & WSEPR (day $\left.{ }^{-1}\right)$ & Reference \\
\hline Northern East China Sea & Apr.-May 2004 & $11.3-16.6$ & $0-14.9(5.8)$ & $0-0.044(0.016)$ & This study \\
Korean coast of the Yellow Sea & Mar.-May 2007-2010 & $6.3-13.3$ & $10.3-34.9(23.4)$ & $0.038-0.111(0.082)$ & Kang et al. (2011) \\
Asan Bay, Korea & Apr.-May 1994 & $6.4-14.4$ & $2.7-16.3(10.4)^{\mathrm{a}}$ & N.I. & Park (1997) \\
Asan Bay, Korea & Mar.-May 1996 & $3.3-11.0$ & $5.3-10.3(8.2)^{\mathrm{a}}$ & N.I. & Park (1997) \\
Southern Yellow Sea & Mar.-May 2001 & $6.7-12.8$ & $5.4-6.3(5.9)$ & $0.015-0.025(0.020)$ & Zhang et al. (2005) \\
Yellow Sea & Apr. 2006 & $4.9-13.4$ & $0-25.4$ & N.I. & Wang et al. (2009) \\
\hline
\end{tabular}

${ }^{a}$ Recalculated from Table 1 in Park (1997); N.I.: No information.

Table 3. Total production of the copepod Calanus sinicus. Values given with respect to the season and water temperature (WT) at which they were collected. Parentheses indicate mean values.

\begin{tabular}{|c|c|c|c|c|c|}
\hline Region & Season & $\mathrm{WT}\left({ }^{\circ} \mathrm{C}\right)$ & Stages & $\begin{array}{c}\text { Production } \\
\left(\mathrm{mg} \mathrm{C} \mathrm{m}^{-3} \text { day }^{-1}\right)\end{array}$ & Reference \\
\hline Northern East China Sea & Apr.-May 2004 & $11.3-16.6$ & CI-adult & $0.02-3.67(0.91)$ & This study \\
\hline Kii Channel, Inland Sea of Japan & Apr. 1987-Mar. 1988 & $8.7-25.9$ & CI-adult & $0.98^{\mathrm{a}}$ & Huang et al. (1993) \\
\hline Northern East China Sea & Jul. 2007 & $12.9-21.9$ & $\mathrm{CI}-\mathrm{CV}$ & $0.03-1.40(0.50)^{\mathrm{b}}$ & Kang (2008) \\
\hline
\end{tabular}

${ }^{\text {a }}$ Estimated from annual production, $358 \mathrm{mg} \mathrm{C} \mathrm{m}^{-3} \mathrm{year}^{-1}$; ${ }^{\mathrm{b}}$ Somatic production estimated by the temperature-dependent growth equations (Uye 1988).

$a$ concentration) was very low, at $9.4 \%$ of the variability of WSEPR of $C$. sinicus, indicating that other factors, e.g. a diet on organisms without Chl a (Calbet \& Saiz 2005, Huo et al. 2008) may also be important for WSEPR.

In general, the WSEPR of adult broadcaster copepods is negatively correlated with increasing body size (or body mass) (Hirst \& Sheader 1997, Hirst \& Bunker 2003), indicating that smaller copepods have a higher WSEPR than larger copepods. The WSEPR of $C$. sinicus significantly decreased with increasing mean body mass of adult females (i.e. from 83.3 to $121.4 \mu \mathrm{g} \mathrm{C}$ ind. $^{-1}$ by station) in this study, supporting previous results.

\section{Production of Calanus sinicus}

Studies on the secondary production of Calanus sinicus have been very limited compared to the EPR of $C$. sinicus (see Tables 2, 3). Total production of $C$. sinicus in this study was similar to that in the Inland Sea of Japan (Huang et al. 1993), and higher than somatic production in the northern ECS in early summer (Kang 2008) (see Table 3). Although there are limits to the direct comparison of production rates of $C$. sinicus due to the different methodology used, it would be helpful to understand the degree of variability in the production rates of $C$. sinicus. Considering the lack of data on secondary production of $C$. sinicus, our estimate of the production of $C$. sinicus can be used to generate new information on secondary production of $C$. sinicus for comparisons of region-specific copepod production.

Considering the importance of $\mathrm{CV}$ in the total production of $C$. sinicus, $\mathrm{CV}$ dominated the population of $C$. sini- cus in early summer in the northern ECS, contributing $46.2-84.6 \%$ of total abundance (Kang 2008). The mean population biomass of juvenile stages of $C$. sinicus was the largest for $\mathrm{CV}$, followed by adult females in late spring in the northern ECS (Kim \& Kang 2018). In our study, the mean biomass of $\mathrm{CV}$ contributed $43 \%$ of total biomass, ranging from 21 to $74 \%$ of total biomass (Fig. 4b). When we consider the contribution of $\mathrm{CV}$ to the production of C. sinicus, the mean production of CV contributed $54 \%$ of total production and $56 \%$ of somatic production, indicating $\mathrm{CV}$ is the most important contributor for total production of $C$. sinicus in spring in the northern ECS.

Peterson et al. (1991) showed that the EPR of copepods accounted for $25 \%$ of total copepod production, summed over all species in Skagerrak. Hirche et al. (2001) showed that the EPR of C. finmarchicus accounted for $27 \%$ of total production, calculated from specific egg production. Kang \& Kang (2005) found that the EPR of Acartia steueri Smirnov, 1936 in Ilkwang Bay accounted for 13.4\% of total production (recalculated from Table 1, including zero EPR). Also, Kang et al. (2007a) showed that the EPR of Acartia omorii Bradford, 1976 in Ilkwang Bay accounted for $14.4 \%$ of total production (recalculated from Table 1, including zero EPR). Our value for the contribution of EPR to total production of $C$. sinicus is lower (e.g. 3.7\% of the total production including zero EPR) than those of other species, including C. finmarchicus, A. steueri, A. omorii, and the total copepod community (Peterson et al. 1991, Hirche et al. 2001, Kang \& Kang 2005, Kang et al. 2007a). 


\section{Acknowledgements}

We thank Prof. AG Hirst for valuable comments on an earlier version of the manuscript and the two anonymous reviewers. We also thank Dr. CR Lee for assistance during the field work and Dr. JH Noh for chlorophyll- $a$ data. We are grateful to the captain and crew of the R/V Eardo for their help during the cruise. This work was partially supported by KIOST projects (PE99811, PE99812 and PE99822).

\section{References}

Banse K (1995) Zooplankton: Pivotal role in the control of ocean production. ICES J Mar Sci 52: 265-277.

Calbet A, Saiz E (2005) The ciliate-copepod link in marine ecosystems. Aquat Microb Ecol 38: 157-167.

Chen CTA, Ruo R, Pai SC, Liu CT, Wong GTF (1995) Exchange of water masses between the East China Sea and the Kuroshio off northeastern Taiwan. Cont Shelf Res 15: 19-39.

Chen CTA, Sheu DD (2006) Does the Taiwan Warm Current originate in the Taiwan Strait in wintertime? J Geophys Res 111: C04005.

Chen WZ, Zheng YZ Chen YQ, Mathews CP (1997) An assessment of fishery yields from the East China Sea ecosystem. Mar Fish Rev 59: 1-7.

Choi KH, Lee CR, Kang HK, Kang KA (2011) Characteristics and variation of size-fractionated zooplankton biomass in the northern East China Sea. Ocean Polar Res 33: 135-147. (in Korean with English abstract)

Gong GC, Chang J, Chiang KP, Hsiung TM, Hung CC, Duan SW, Codispoti LA (2006) Reduction of primary production and changing of nutrients ratio in the East China Sea: effect of the Three Gorges Dam? Geophys Res Letters 33: L07610.

Hirche HJ, Brey T, Niehoff B (2001) A high-frequency time series at Ocean Weather Ship Station M (Norwegian Sea): population dynamics of Calanus finmarchicus. Mar Ecol Prog Ser 219: 205-219.

Hirst AG, Bunker AJ (2003) Growth of marine planktonic copepods: Global rates and patterns in relation to chlorophyll $a$, temperature, and body weight. Limnol Oceanogr 48: 19882010.

Hirst AG, Lampitt RS (1998) Toward a global model of in situ weight-specific growth in marine planktonic copepods. Mar Biol 132: 247-257.

Hirst AG, Peterson WT, Rothery P (2005) Errors in juvenile copepod growth rate estimates are widespread: problems with Moult Rate method. Mar Ecol Prog Ser 296: 263-279.

Hirst AG, Sheader M (1997) Are in situ weight-specific growth rates body-size independent in marine planktonic copepods? A re-analysis of the global syntheses and a new empirical model. Mar Ecol Prog Ser 154: 155-165.

Huang C, Uye S, Onbé T (1993) Geographic distribution, seasonal life cycle, biomass and production of a planktonic copepod Calanus sinicus in the Inland Sea of Japan and its neighboring Pacific Ocean. J Plankton Res 15: 1229-1246.

Huo YZ, Wang SW, Sun S, Li CL, Liu MT (2008) Feeding and egg production of the planktonic copepod Calanus sinicus in spring and autumn in the Yellow Sea, China. J Plankton Res 30: $723-734$.

Hwang SW, Kang HK, Son YB, Jang MC, Choi KH (2013) Collapse of the crustacean mesozooplankton in the northern East China Sea: Effects of the Three Gorges Dam? J Coast Res 29: 1464-1469.

Kang HK (2012) Effects of suspended sediments on reproductive responses of Paracalanus sp. (Copepoda: Calanoida) in the laboratory. J Plankton Res 34: 626-635.

Kang HK, Kang Y (2005) Production of Acartia steueri (Copepoda: Calanoida) in Ilkwang Bay, southeastern coast of Korea. J Oceanogr 61: 327-334.

Kang HK, Kang Y, Park C (2007a) Production of Acartia omorii (Copepoda: Calanoida) in Ilkwang Bay, southeastern coast of Korea. J Mar Sys 67: 236-244.

Kang HK, Lee CR, Choi KH (2011) Egg production rate of the copepod Calanus sinicus off the Korean coast of the Yellow Sea during spring. Ocean Sci J 46: 133-143.

Kang HK, Shin CW, Jeon D (2015) Effect of El Niño/La Niña on mesozooplankton biomass in the northwestern subtropical $\mathrm{Pa}-$ cific Warm Pool and the northern East China Sea. Ocean Polar Res 37: 189-200. (in Korean with English abstract)

Kang JH, Kim WS, Jeong HJ, Shin K, Chang M (2007b) Why did the copepod Calanus sinicus increase during the 1990s in the Yellow Sea? Mar Environ Res 63: 82-90.

Kang JH, Seo MH, Kwon OY, Kim WS (2013) Diel vertical migration of the copepod Calanus sinicus before and during formation of the Yellow Sea Cold Bottom Water in the Yellow Sea. Acta Oceanol Sin 32: 99-106.

Kang KA (2008) Mesozooplankton distribution and population dynamics of Calanus sinicus (Copepoda: Calanoida) in the northern East China Sea in summer. MS Thesis. Pukyong National University, Korea. (in Korean with English abstract)

Kang YS, Hong SY (1998) Seasonal variations in distribution, population structure and prosome length of Calanus sinicus (Copepoda: Calanoida) in the southern waters of Korea. J Korean Soc Oceanogr 33: 28-34.

Kim D, Choi SH, Kim KH, Shim J, Yoo S, Kim CH (2009) Spatial and temporal variations in nutrient and chlorophyll- $a$ concentrations in the northern East China Sea surrounding Cheju Island. Cont Shelf Res 29: 1426-1436.

Kim G, Kang HK (2018) Grazing impact of the copepod Calanus sinicus on phytoplankton in the northern East China Sea in late spring. Ocean Sci J 53: 225-237.

Kim JY, Kang YS, Oh H, Suh YS, Hwang JD (2005) Spatial distribution of early life stages of anchovy (Engraulis japonicus) and hairtail (Trichiurus lepturus) and their relationship with oceanographic features of the East China Sea during the 1997-1998 El Niño Event. Estuar Coast Shelf Sci 63: 13-21.

Kim SH, Lim DH (1999) Spatial and temporal distribution of Calanus sinicus (Copepoda: Calanoida) in the Yellow Sea with its body length variation. Collection of dissertations, Yongin Univ. 17: 215-225. (in Korean with English abstract)

Kimmerer WJ (1987) The theory of secondary production calculations for continuously reproducing populations. Limnol Oceanogr 32: 1-13.

Kimmerer WJ, McKinnon AD (1987) Growth, mortality, and 
secondary production of the copepod Acartia tranteri in Westernport Bay, Australia. Limnol Oceanogr 32: 14-28

Kimmerer WJ, Hirst AG, Hopcroft RR, McKinnon AD (2007) Estimating juvenile copepod growth rates: corrections, intercomparisons and recommendations. Mar Ecol Prog Ser 336: 187-202.

Kiørboe T (1997) Population regulation and role of mesozooplankton in shaping marine pelagic food webs. Hydrobiologia 363: 13-27.

Liang D, Uye S, Onbé T (1994) Production and loss of eggs in the calanoid copepod Centropages abdominalis Sato in Fukuyama Harbor, the Inland Sea of Japan. Bull Plankton Soc Japan 41: 131-142.

Lie HJ, Cho CH (2016) Seasonal circulation patterns of the Yellow and East China Seas derived from satellite-tracked drifter trajectories and hydrographic observations. Prog Oceanogr 146: 121-141.

Lie HJ, Cho CH, Lee JH, Lee S (2003) Structure and eastward extension of the Changjiang River plume in the East China Sea. J Geophys Res 108: 3077.

Ministry of Oceans and Fisheries (MOF) (2006) Prediction of the marine ecosystem variation in the East China Sea due to the long term climate change: Long term change of the biogeochemical cycling and biological processes in the East China Sea-Observation and Prediction. BSPN 33600-1795-1, 206 pp. (in Korean with English abstract)

Niehoff B (2007) Life history strategies in zooplankton communities: The significance of female gonad morphology and maturation types for the reproductive biology of marine calanoid copepods. Prog Oceanogr 74: 1-47.

Park C (1997) Seasonal distribution, egg production and feeding by the marine copepod Calanus sinicus in Asan Bay, Korea. J Korean Soc Oceanogr 32: 85-92

Parsons TR, Maita Y, Lalli CM (1984) A Manual of Chemical and Biological Methods for Seawater Analysis. Pergamon Press, Oxford, 173 pp.

Peterson WT (1988) Rates of egg production by the copepod Calanus marshallae in the laboratory and in the sea off Oregon, USA. Mar Ecol Prog Ser 47: 229-237.

Peterson WT, Gómez-Gutiérrez J, Morgan, CA (2002) Crossshelf variation in calanoid copepod production during summer 1996 off the Oregon coast, USA. Mar Biol 141: 353-365.

Peterson WT, Tiselius P, Kiørboe T (1991) Copepod egg production, molting and growth rates and secondary production, in the Skagerrak in August 1988. J Plankton Res 13: 131-154.
Pu XM, Sun S, Yang B, Zhang GT, Zhang F (2004) Life history strategies of Calanus sinicus in the southern Yellow Sea in summer. J Plankton Res 26: 1059-1068.

Rey-Rassat C, Bonnet D, Irigoien X, Harris R, Head R, Carlotti F (2004) Secondary production of Calanus helgolandicus in the Western English Channel. J Exp Mar Biol Ecol 313: 29-46.

Runge JA, Roff JC (2000) The measurement of growth and reproductive rates. In: ICES Zooplankton Methodology Manual (eds Harris RP, Wiebe PH, Lenz J, Skjoldal HR, Huntley M). Academic Press, London, pp. 401-454.

Uye S (1988) Temperature-dependent development and growth of Calanus sinicus (Copepoda: Calanoida) in the laboratory. Hydrobiologia 167/168: 285-293.

Uye S (2000) Why does Calanus sinicus prosper in the shelf ecosystem of the Northwest Pacific Ocean? ICES J Mar Sci 57: $1850-1855$.

Uye S, Murase A (1997) Relationship of egg production rates of the planktonic copepod Calanus sinicus to phytoplankton availability in the Inland Sea of Japan. Plankton Biol Ecol 44: $3-11$.

Verity PG, Smetacek V (1996) Organism life cycles, predation, and the structure of marine pelagic ecosystems. Mar Ecol Prog Ser 130: 277-293.

Wang R, Zuo T, Wang K (2003) The Yellow Sea Cold Bottom Water-an oversummering site for Calanus sinicus (Copepoda, Crustacea). J Plankton Res 25: 169-183.

Wang S, Li C, Sin S, NIng X, Zhang W (2009) Spring and autumn reproduction of Calanus sinicus in the Yellow Sea. Mar Ecol Prog Ser 379: 123-133.

Yebra L, Kobari T, Sastri AR, Gusmão F, Hernández-León S (2017) Advances in biochemical indices of zooplankton production. In: Advances in Marine Biology (ed Curry BE). Vol. 73, Academic Press, Oxford, pp. 157-240.

Zhang GT, Sun S, Yang B (2007a) Summer reproduction of the planktonic copepod Calanus sinicus in the Yellow Sea: influences of high surface temperature and cold bottom water. J Plankton Res 29: 179-186.

Zhang GT, Sun S, Zhang F (2005) Seasonal variation of reproduction rates and body size of Calanus sinicus in the Southern Yellow Sea, China. J Plankton Res 27: 135-143.

Zhang J, Liu SM, Ren JL, Wu Y, Zhang GL (2007b) Nutrient gradients from the eutrophic Changjiang (Yangtze River) Estuary to the oligotrophic Kuroshio waters and re-evaluation of budgets for the East China Sea Shelf. Prog Oceanogr 74: 449-478. 